\title{
O MODELO DE DESENVOLVIMENTO DA AMÉRICA LATINA E SUAS IMPLICAÇÕES NA FORMAÇÃO PROFISSIONAL EM SERVIÇO SOCIAL
}

\author{
Cristiana Costa Lima \\ Universidade Federal do Maranhão (UFMA)
}

O MODELO DE DESENVOLVIMENTO DAAMÉRICA LATINA E SUAS IMPLICAÇÕES NA FORMAÇÃO PROFISSIONAL EM SERVIÇO SOCIAL

Resumo: O texto aborda a formação profissional em Serviço Social frente ao modelo de desenvolvimento estabelecido na América Latina na contemporaneidade. Apresenta as particularidades do modelo "neodesenvolvimentista" na região, revelando seus traços de continuidade do modelo neoliberal, e problematiza o impacto dessas transformações na formação profissional em Serviço Social.

Palavras-chave: Modelo de desenvolvimento, Serviço Social, formação profissional.

THE LATIN AMERICA DEVELOPMENT MODEL AND ITS IMPLICATIONS ON PROFESSIONAL FORMATION IN SOCIAL WORK

Abstract: The text approaches the professional formation in Social Work against development model established in Latin America in contemporaneity. Presents the particularities of "new developmentalist" model in the region, revealing its traces of continuity of the neoliberal model, and discusses the impact of these transformations in professional formation in Social Work.

Keywords: Development model, Social Work, professional formation. 


\section{INTRODUÇÃO}

As particularidades do desenvolvimento da América Latina, especialmente na contemporaneidade, impõem desafios aos pesquisadores e profissionais comprometidos com a efetiva emancipação humana nessa região. Há que se ter claro entendimento do que se passa no continente do ponto de vista das políticas desenvolvimentistas em gestação e suas implicações para a reprodução social latina.

O que objetivamos neste texto é exatamente desnudar a ideologia do neodesenvolvimentismo em voga, especialmente no tocante aos impactos que ele traz nas manifestações da questão social na região. E, ainda, como esse modelo tem determinado as mediações profissionais do Serviço Social e, consequentemente, o caráter da formação profissional.

Com isso, pretendemos contribuir para a reflexão que resgate o projeto ético-político do Serviço Social, sobretudo em seu comprometimento com os movimentos de resistência na América Latina e na região amazônica.

\section{O MODELO DE DESENVOLVIMENTO NA AMERICA LATINA}

As crises são inerentes ao capitalismo e afetam as classes fundamentais e a atuação do Estado - este, principal instrumento utilizado pelas classes para o enfrentamento às crises cíclicas do sistema. A correlação de forças, os projetos trazidos pelas classes e a hegemonia construída por elas se inter-relacionam com a forma e o tipo de mediação que o Estado processará nesse cenário.

As respostas dadas pelo Estado impactam diretamente as estratégias de acumulação da riqueza, o trabalho e os meios ideopolíticos que, sustentados nessa base material, apresentam-se como instrumentos formadores de práticas, ideologias e subjetividades, ou seja, a reprodução social.

O projeto hegemônico em curso na sociedade tem alguns traços. Um desses traços é o papel ativo do Estado na indução do crescimento econômico e de políticas que devem possibilitar uma estratégia de coesão, consenso e alianças de classe.

[...] o Estado passa a desempenhar um papel central neste projeto dando andamento ao processo da sua contrarreforma, favorecendo os espaços para a produção de super-lucros. Por isso mesmo, inova suas práticas ideológicas e produtivas, seja nos países centrais, seja nos periféricos, patrocinando uma série de transformações nos padrões de acumulação e reprodução vigentes. (MOTA, 2012, p. 31-32).

Contemporaneamente, esse projeto vem sendo denominado de neodesenvolvimentista ${ }^{1}$, orientado por princípios do social-liberalismo, que advoga a existência de crescimento econômico com justiça social, principalmente através das chamadas políticas de alívio à pobreza.

Liberal porque, como destaca Gonçalves (2012, p. 661-662), caracteriza-se por: baixa propensão a políticas setoriais, liberalização comercial, ausência de restrição ao investimento estrangeiro direto, minimização da função alocativa do Estado (investimento, políticas setoriais e planejamento), incorporação da função distributiva do Estado de forma moderada (valoriza a distribuição de renda, mas ignora a distribuição de riqueza); defesa das reformas institucionais orientadas para a correção de falhas no mercado e de governo (função reguladora do Estado) e grande ênfase na estabilização macroeconômica (controle da inflação e equilíbrio fiscal).

Social, porque implementa uma política de consolidação de um sistema de proteção social, baseada fortemente em programas de transferência de renda para o combate à pobreza. A CEPAL, por exemplo, registra, no período de 1998 a 2010, a existência de 40 programas de transferência de renda na região latina. Dentre eles, estão o Asignación Universal por Hijo para Protección Social (2009-), Familias por la Inclusión Social (2005-) e Jefas y Jefes de Hogar Desocupados (2002-2005), na Argentina; Bolsa Família (2003-), no Brasil; Chile Solidário (2002), no Chile; Familias en Acción (2001) e Subsídios Condicionados a la Asistencia Escolar (2005-) e Red Juntos (Red para la superación de la pobreza extrema) (2007-), na Colômbia. A essa rede de proteção social, somam-se a política de incentivo ao consumo através da disponibilização de crédito e incremento da média salarial recebida pelos trabalhadores.

À medida que esse projeto toma forma vai expressando uma coalisão entre classes antagônicas que favorece ao grande capital, atende necessidades do trabalho mas não afeta a concentração da riqueza, no máximo redistribui a renda entre setores da mesma classe trabalhadora, mas sem afetar a acumulação da riqueza.

Isso significa que essas políticas podem, de fato, alterar o desenho da pobreza e da miséria, mas não alteram, não mudam, não revertem a histórica desigualdade social na America Latina. Essa fase supostamente de novo desenvolvimento no Brasil e na América Latina traz mais continuidade do que alguma ruptura efetiva com o padrão e o período anterior. Elemento típico da nossa modernização conservadora.

O real significado do discurso de um novo desenvolvimentismo efetiva-se por meio de uma forte intervenção do Estado para beneficiar grandes grupos econômicos. Tal projeto centra-se em grandes projetos e na exportação de commodities, contribuindo para expropriação e exploração de massa de trabalhadores. Estamos assistindo na América Latina a um processo que tem uma grande particularidade política: o discurso da negação ao 
neoliberalismo ao mesmo tempo em que afirma que sua superação se faz à base de desenvolvimentismo. Ou seja, crescimento econômico feito sob expansão da grande propriedade, em cima das commodities, do mercado comercial, das riquezas do subsolo (pré-sal), do minério, da soja, do milho e outros.

\begin{abstract}
Este modelo incentiva la multiplicación de empreendimientos exclusivamente destinados a comercializar productos básicos. Mientras crece la influencia del agro-negocio, las inversiones extranjeras consolidan la especialización petrominera. Todas las potencias buscan asegurarse el aprovisionamiento de insumos latinoamericanos, afianzando la inserción de la zona como granja o socavón de la economía mundial. (KARTZ, 2012, p. 718).
\end{abstract}

Nesse cenário, a Amazônia tem sido apenas mais um espaço de saque, sem nenhuma perspectiva de desenvolvimento efetivo para a região. Os projetos minerais são pensados para durar no máximo três ou quatro décadas e, depois disso, as multinacionais vão embora; os países onde se instalam especializam-se em produzir gado, soja (para consumo de animal criado na Europa) e minério. A título de exemplo, registra Leal (2013):

[...] em 30 anos, retirou-se 50 milhões de toneladas de manganês do Amapá [...] deixaram lá apenas uma imensa cratera cercada de mato; toda a jazida de cassiterita de ManausCaracaraí foi devastada, dizimando os índios na região².

Os países da região têm optado por reduzir a pobreza e a desigualdade via programas de assistência social. Mota (2008) afirma que tem havido uma alteração na definição da questão social, bem como na sua forma de enfrentamento na medida em que transforma os desempregados e os subempregados em clientela da assistência social em detrimento ao direito ao trabalho. Há, assim, um "[...] deslizamento da raiz do fenômeno e da noção de questão social para as genéricas denominações de 'exclusão', pobreza, combate à fome." (MOTA, 2008, p. 41). Programas são desenvolvidos em cima da cultura de que superamos o neoliberalismo, sem, entretanto, nenhuma reforma estrutural de fundo que altere as condições postas. Ao contrário, perpetua-se o receituário neoliberal para as políticas sociais na região.

\section{IMPLICAÇÕES À FORMAÇÃO EM SERVIÇO SOCIAL FRENTE AO MODELO DE DESENVOLVIMENTO NA AMERICA LATINA}

A partir das últimas décadas do século $X X$, o Serviço Social tem sofrido profundas transformações em todo o continente nos marcos das respostas dadas pelo neoliberalismo frente à crise capitalista a partir da década de 1970 . No que diz respeito à política de formação profissional proposta pelo ajuste neoliberal, o que se percebe é um controle sobre os processos de formação acadêmica a partir de um padrão profissional voltado para exigências imediatas do mercado.

A proposta dos organismos internacionais (FMI e Banco Mundial) para os países dependentes afirma a necessidade de uma formação por competência, pragmática, flexível, polivalente, em detrimento de uma formação profissional crítica inserida nas lutas cotidianas das classes trabalhadoras e com horizonte societal claramente definido.

A hegemonia do capital financeiro, sua volatilidade, rapidez inédita, o curto prazo da especulação financeira contaminam toda a sociedade pela pressão do aqui e agora. O trabalho é tornado flexível e descartável. Só se produz o que é demandado. Naturaliza-se a realidade social e a sociedade não encontra alternativa. Se essas afirmativas estão corretas, pode-se afirmar que um novo perfil de trabalhador se gesta na sociedade sob o domínio do capital financeiro.

É nessa conjuntura que cada vez mais aparecem para o Serviço Social demandas por intervenções isoladas junto a famílias, práticas terapêuticas, ações de responsabilidade individual ou social, práticas clínicas. No contexto em que vivemos, com os apelos aos subjetivismos, adaptação de comportamentos, amenização de conflitos, os resultados se apresentam como se fossem decorrência da mera vontade do sujeito. Esse cenário tem implicações não só no surgimento de novas demandas profissionais como também de redimensionar a formação profissional.

Há uma dicotomia entre conhecimento e intervenção, polarizando na centralidade da prática que coloca em evidencia o pragmatismo. Nessa visão funcionalista, a preocupação reside nos comportamentos e as respectivas funções que preenchem. A ênfase sobre o controle do comportamento passa a ser um procedimento curricular por intermédio dos objetivos educacionais. Para tal, definem-se os comportamentos finais a serem atingidos e os critérios que possibilitam avaliar. Diante desse quadro, o trabalhador deve ser desespecializado, desregulamentado, polivalente e multifuncional.

Partimos do pressuposto de que a formação profissional sempre está orientada para a intervenção profissional. Porém, não é o mercado que deve definir a formação profissional, pois esta se refere à aquisição de competências teóricas, técnico-operativas e ético-políticas que se conjugam e se expressam na intervenção profissional.

Um dos desafios postos para a formação profissional na atualidade consiste em interpretar as transformações que afetam o mundo da produção, a esfera do Estado e das políticas que nos permitam 
conhecer as novas mediações nas manifestações da questão social frente às demandas postas à profissão e às respostas dadas por ela. Essa concepção parte do entendimento da profissão como totalidade e não reduzida a uma perspectiva técnico-operacional que dê respostas imediatas ao mercado.

Entendemos que a formação profissional deve possibilitar uma compreensão das transformações contemporâneas do capital que modificam e determinam os espaços de atuação profissional dos assistentes sociais. Nesse sentido, a formação dos assistentes sociais deve ser generalista no sentido de possibilitar ao conjunto do alunado uma leitura da realidade na qual está inserido.

Diante disso, os pressupostos básicos para formação profissional devem estabelecer uma relação estreita com a questão social, base de fundação sócio-histórica da profissão e constitutiva da relação profissão-realidade. Ou seja, a questão social deve ser entendida como o eixo fundamental do Serviço Social e, portanto, o eixo ordenador da estrutura curricular das unidades de ensino do Serviço Social em toda a América Latina.

\section{CONCLUSÃO}

A diretiva dos organismos internacionais introduziu uma série de medidas (exame nacional de curso, mestrados profissionalizantes, substituição dos currículos mínimos por diretrizes curriculares, cursos sequenciais, ensino à distância em todos os níveis), no sentido da privatização das políticas sociais, de favorecimento da expansão dos serviços privados, de diversificação e massificação do ensino e de reconfiguração das profissões, conforme acordo da OMC, como destaca Leher (1998). O ensino a distância e o ensino presencial privado, hoje, estão em franca expansão em toda a América Latina. Tal processo

Ocorre para configurar nichos de valorização do capital médio, num período em que o capitalismo promove uma intensa oligopolização do capital, com tendências de concentração e fusão de capitais, e dificuldades de investimento produtivo e de valorização. Constitui-se ainda uma via de acesso ao fundo público e ao crédito, a exemplo da discussão acerca do apoio do BNDES a essas instituições, na perspectiva de valorização do lucro privado fácil e rápido, tendência esta que vem crescendo no contexto da recente crise. (CONSELHO FEDERAL DE SERVIÇO SOCIAL (2011).

O que está em questão com essa política de expansão é a mudança no sentido e conceituação de universidade: trata-se de uma perspectiva que restringe o sentido de espaço de pesquisa e elaboração de conhecimento e amplia o sentido da produção e titulação. Sem considerar relevante a qualidade técnica, ética e social desses cursos, voltase exclusivamente, para responder às exigências do capital financeiro com expansão quantitativa e submissão às demandas do mercado.
O ensino à distância e as estratégias de privatização da educação presencial aparecem com o discurso da democratização do acesso, mas na verdade é uma resposta aos parâmetros internacionais de competitividade e atratividade, no contexto da mundialização do capital, ao mesmo passo em que reproduz sua ideologia.

$\mathrm{Na}$ Amazônia, as contradições presentes estão, de forma inequívoca, relacionadas à acumulação capitalista mundial. A esses processos historicamente construídos, somam-se outros em razão dessa acumulação, especialmente em função da crise capitalista contemporânea, configurando uma realidade regional onde se pode encontrar, entre tantos outros fenômenos, uma massiva desigualdade social (evidente no empobrecimento de sua população); uma reincidente agressão à natureza (à mostra nos desmatamentos, nas queimadas e na poluição dos rios); um crescimento da violência rural e urbana (decorrente de conflitos de terra e crescimento desordenado da população e das cidades); uma permanente ameaça aos povos da floresta (historicamente expropriados de suas terras); e o crescimento do trabalho infantil e escravo.

As manifestações da questão social na Amazônia são repletas de particularidades que colocam aos pesquisadores um esforço contínuo de apreender a sua lógica e o movimento que as classes - em especial os trabalhadores, incluindo-se aí os assistentes sociais - têm dado ao enfrentamento destas questões. Nesse sentido, as determinações da questão regional amazônica não são aparentes, pois se apresentam profundamente fragmentadas e como se fossem alheias a uma profissão cuja ação imediata recai sobre os serviços assistenciais.

A questão regional amazônica é reflexo da questão social na América Latina, expressa pelas relações de forças econômicas e das classes, postas pelos países centrais aos países periféricos e dependentes como expressão das relações imperialistas. Nesse contexto, devemos compreender que

O Serviço Social como totalidade histórica evidencia-se na relação que se estabelece entre as mudanças qualitativas das determinações da profissão, isto é, dos seus elementos constitutivos (dimensão interventiva, produção de conhecimento, a formação profissional e a organização política) e as determinações, também qualitativas, das totalidades societárias concretas às quais pertença o Serviço Social. (CARDOSO, 2007, p. 35-36).

Assim, a dimensão crítica de construção de um projeto de efetiva emancipação humana só se concretiza caso haja um forte comprometimento dos profissionais do Serviço Social com os movimentos de resistência na região. 


\section{REFERÊNCIAS}

CARDOSO, Franci. Fundamentos históricos e teórico-metodológicos do Serviço Social: tendências quanto à concepção e organização de conteúdos na implementação das diretrizes curriculares. Temporalis, Brasília, DF, ano VII, n. 14, p-31-53, jun./dez. 2007.

\section{COMISSÃO ECONÔMICA PARA AMÉRICA LATINA} E O CARIBE. División de Desarrollo Social. Santiago de Chile, 2010.

CONSELHO FEDERAL DE SERVIÇO SOCIAL. Sobre a incompatibilidade entre graduação à distância e Serviço Social. Brasília, DF, 2011. Disponível em: <http://www.abepss.org.br/briefing/ documentos/Documento-Incompatibilidade-entreGraduacao-Distancia-ServicoSocial.pdf>. Acesso em: 15 out. 2011.

GONÇALVES, Reinaldo. Novo desenvolvimentismoe liberalismo enraizado. Serviço Social e Sociedade, São Paulo, v. 112, p. 637-671, out./dez. 2012.

KATZ, Claudio. Los atolladeros de la economía latinoamericana. Serviço Social e Sociedade, São Paulo, v. 112, p. 711-728, 2012.

LEAL, Aluísio Lins (UFPA). A conjuntura política latino-americana e a questão da região amazônica. São Luís, 2013. Conferência proferida no Programa de Pós-Graduação em Políticas Públicas da UFMA, São Luís, em 2 de abril de 2013

LEHER, R. Da ideologia do desenvolvimento à ideologia da globalização: a educação como estratégia do Banco Mundial para o "alívio" da pobreza. 1998. Tese (Doutorado em Educação) - Faculdade de Educação, Universidade de São Paulo, São Paulo, 1998.

MOTA, Ana Elizabete (Org). 0 mito da assistência: ensaios sobre Estado, política e sociedade. 2. ed. São Paulo: Cortez, 2008.

(Org). Desenvolvimentismo e construção de hegemonia: crescimento econômico e reprodução da desigualdade. São Paulo: Cortez, 2012.

\section{NOTAS}

1 Compreendemos aqui o neodesenvolvimentismo como uma nova faceta do liberalismo em sua estratégia de intervenção estatal que propicia a estabilização econômica favorável à reprodução do sistema do capital. Não altera, inclusive, as bases do neoliberalismo implantado na região latina, ainda que tenha se expressado via governos oriundos de uma agenda contrária ao Consenso de Washington, a exemplo do Brasil nas gestões Lula da Silva - Dilma Roussef, da Argentina, sob o casal Néstor e Cristina Kirchner, e do Chile de Ollanata Hulama, mas também fortemente enraizado na Colômbia de Álvaro Uribe e Juan Manuel Santos, no Chile de Sebastián Piñera e no México de Peña Nieto, sob forte influência do governo estadunidense. Nestes últimos países (México, Chile, Colômbia), acentua-se o viés liberal de suas políticas, complementando a continuidade do livre-comércio e das privatizações (KATZ, 2012, p. 712).

2 Conferência do Prof. Aluísio Lins Leal (UFPA) sobre A conjuntura política latino-americana e a questão da região amazônica, realizada pelo GSERMS (Grupo de Pesquisa em Serviço Social e Movimento Social) e Observatório de Políticas Públicas e Lutas Sociais, vinculados ao Programa de Pós-Graduação em Políticas Públicas da UFMA, São Luís, em 02 de abril de 2013.

\section{Cristiana Costa Lima}

Assistente Social

Doutora em Políticas Públicas pela Universidade Federal do Maranhão (UFMA)

Professora da Universidade Federal do Maranhão.

E-mail: costalima.cristiana@gmail.com

\section{Universidade Federal do Maranhão- UFMA}

Cidade Universitária do Bacanga

Avenida dos Portugueses, 1966-Bacanga

85.085-580- São Luís-Ma 